\title{
The Possibility of China's Industrial Park Management Committee to Promote Interenterprise Cooperative Innovation in the Park: A Trilateral Evolutionary Game Perspective
}

\author{
Zhuopin Guo $\mathbb{D}^{1},{ }^{1}$ Jie Zhen $\mathbb{D}^{2},{ }^{2}$ Yiying $Q u^{2}$ and Hao Ren ${ }^{1}$ \\ ${ }^{1}$ School of Economics and Management, Tongji University, Shanghai, China \\ ${ }^{2}$ Business School, East China University of Political Science and Law, Shanghai, China \\ Correspondence should be addressed to Jie Zhen; jetzhen@163.com
}

Received 13 February 2020; Revised 10 August 2020; Accepted 8 September 2020; Published 6 October 2020

Academic Editor: Lucia Valentina Gambuzza

Copyright (c) 2020 Zhuopin Guo et al. This is an open access article distributed under the Creative Commons Attribution License, which permits unrestricted use, distribution, and reproduction in any medium, provided the original work is properly cited.

Under China's distinct policy-driven agglomeration approach, the Chinese industrial park displays a low degree of industrial relevance and weak cooperation among enterprises in the park. The key to solving this problem lies in the guiding role of the park management committee. Accordingly, this study constructs a trilateral evolutionary game model of interenterprise cooperative innovation inside the industrial park under the supervision of the park management committee, leadership of the core enterprises, and with the participation of the small- and medium-sized enterprises. Through simulation analysis, this study explores the influencing factors behind the trilateral cooperative innovation strategy choices. Results show that (1) the park management committee, core enterprises, and small- and medium-sized enterprises have different degrees of influence on each other's willingness to participate in cooperative innovation; (2) small- and medium-sized enterprises are sensitive to the management committee's policy support, and core enterprises are sensitive to the management committee's financial support; (3) core enterprises are more sensitive to penalties and income distribution than small- and medium-sized enterprises; (4) the degree of resource complementarity and trust among enterprises has a profound effect on core enterprises and small- and medium-sized enterprises' willingness to participate in cooperative innovation.

\section{Introduction}

As a local economic carrier, China's industrial parks have played an essential role in promoting the high-quality development of the regional economy and the optimisation of the industrial structure [1]. The statistics of China Development Zone Yearbook and China Torch Statistical Yearbook shows that by the end of 2018, only two types of industrial parks, namely, national high-tech and economic development zones, have created a GDP of 17,081.63 billion yuan, which accounted for a quarter of China's total GDP. The industrial park has become the main platform of China's industrial transformation and upgrading [2]. As a suborganisation of the local government, the industrial park management committee executes government functions and plays a leading role in the sustainable development of the park [3]. In addition, through the introduction of preferential policies on land, finance, taxation, and talents, it has promoted the rapid expansion of the industrial park for four decades in terms of economics and innovation $[4,5]$. However, under this government-led management model, enterprises enter the park only to obtain policy dividends; less consideration is given to the degree of industrial relevance inside the industrial park, resulting in a low degree of industrial agglomeration [6,7]. Most industrial parks also attach extra importance to establishing enterprise whilst undervaluing the importance of bolstering the enterprises inside the park. The lack of connection and communication in enterprises gathering together severely restricts the cooperation and innovation of enterprises inside the industrial park as well as the transformation and upgrading of its industrial structure [8].

Improving the agglomeration effect of the industrial park requires the enterprises to exchange information and 
knowledge through various formal and informal communications, which generate interaction and complementarity to obtain the benefits of knowledge spillovers [9, 10]. Enterprises can also reduce innovation costs and innovation risk [11]. In this process, the industrial park management committee, as a policymaker and resource coordinator, can help enterprises find partners in the park to engage in joint research and development via a built platform [12]. The management committee can also perform coordination and supervision functions to improve the degree of trust in cooperation between enterprises [13]. Therefore, a considerably high success rate is anticipated in the joint research and development among enterprises inside the park; moreover, the research and development alliance is expected to be highly stable, which can be effective in promoting the comprehensive integration of the industrial chain inside the industrial park and can achieve better transformation and upgrading [14]. However, as far as the actual situation in China is concerned, many problems remain in the practice of interenterprise cooperative innovation in most of the industrial parks, such as the lack of communication and cooperation platforms, inconsistent target cognition among enterprises, and insufficient guidance and supervision. By contrast, interenterprise cooperation should be a voluntary behaviour based on trust. Unfamiliarity and relatively low trust level among the enterprises will easily lead to free-riding behavior [15], which will then weaken the guidance effect of the park management committee; the latter will lead to a lack of motivation for enterprises to participate in collaboration innovation and a low efficiency in cooperative innovation.

The industrial park management committee should play an essential role in promoting and improving the effectiveness of the interenterprise cooperative innovation in the industrial park. However, from the existing research on cooperative innovation, the focus remains at the microlevel (individual enterprise) and the macrolevel (whole network). At the microlevel, the focus lies on the effect of enterprise capabilities such as enterprise's exploration and exploitation capability $[16,17]$, knowledge absorption and integration capability $[18,19]$, knowledge base [20], and dynamic capability [21] on collaborative innovation performance. For example, the company's moderate exploration and exploitation capabilities can help companies obtain complementary innovation resources and improve cooperative innovation performance $[22,23]$. Najafi-Tavani et al. pointed out that internal research and development capabilities, especially absorptive capabilities, are highly linked to collaborative innovation performance [24]. The macrolevel is based on the characteristics of the overall structure of the network, such as the centrality and stabilisation of the network [25], network structure hole [26-28], network density [29], network connectivity [30], and the coupling structure of the network [31] to examine its effect on cooperative innovation.

However, relatively few studies have been conducted from the perspective of the middle level, that is, the perspective of interfirm relations. The existing research is based on two-way game theory to analyse cooperation strategy between two enterprises. Arsenyan et al. introduced factors such as cooperative innovation excess returns, excess return distribution coefficients, additional default benefits, and default costs to construct an evolutionary game model of cooperative innovation among asymmetric enterprises; they then analysed their cooperative innovation strategies [32]. Babu and Mohan analysed the innovation strategy of upstream and downstream firms in the supply chain by establishing a dynamic game model. They pointed out that the profits of cooperative innovation between the relative enterprises in the supply chain are higher than in the case of noninnovation or independent innovation [33]. On this basis, some scholars introduce the intermediary agencies into the interenterprise knowledge transfer game model to analyse the factors that affect the returns of game subjects and the choice of their knowledge transfer strategies in the presence of intermediary agencies [34]. Mêgnigbêto introduced the government into the evolutionary game model of universities and enterprises to build a three-way evolutionary game model. The specific evolutionary path and influencing factors were determined via numerical simulations; subsequently, the input cost, extra income, policy support, and punishment mechanism were found to have a remarkable effect on the evolutionary path [35].

Even at the middle level, the industrial park has been excluded in the research field, and the vital role of the park management committee in interenterprise cooperative innovation has not been considered in the literature. Some literature introduces government and other intermediary institutions into the game model as exogenous variables. However, the government mentioned here is not the park management committee but a first-level local government. Conversely, the literature does not consider government as one of the main subjects to introduce into the interenterprise's cooperation game model. Inside the industrial park, the mechanisms of the interenterprise cooperative innovation game strategies will evolve with the participation of the park management committee as one of the main bodies. Therefore, this article regards the park management committee as one of the main game subjects of interenterprise cooperative innovation game model and analyses the influence of the park management committee on the process of cooperative innovation in terms of funding and policy support. By constructing a trilateral evolution game model of the park management committee, core enterprises, and small- and medium-sized enterprises in the park clarify the evolutionary stability strategy of the trilateral evolution game under different situations to analyse the cooperative innovation mechanism of the tripartite subjects. They also clarify the influencing factors of the interenterprise cooperative innovation strategy selection inside the industrial park through numerical analysis.

\section{Establishment of Tripartite Game Payment Matrix for Interenterprise Cooperation Innovation in the Industrial Park}

2.1. Model Assumptions. Core enterprises in the industrial park such as the world's top 500 enterprises can attract massive relative small- and medium-sized enterprises to gather inside the industrial park to provide technical assistance and production services for the core enterprises. 
Core enterprises have advantages such as strong financing capabilities as well as strong market and technology development capabilities. However, for core enterprises that pursue large-scale production, researching and developing products and technologies which face frequent changes in technology and unstable market demand are obviously an expensive choice. If the core enterprises rely solely on their own capabilities for technology research and product development, reducing the operating costs and improving the economic efficiency of enterprises are not conducive, thereby preventing them from adapting to intense market competition. Conversely, despite the difficulty in obtaining all the funds and market resources vital for innovation via the exclusive efforts of small- and medium-sized firms, compared with core enterprises, they have the advantages such as flexible operating mechanisms, low operating costs, high efficiency, and rapid transformation. Therefore, the core enterprises and small- and medium-sized enterprises can form a mutually beneficial symbiotic cooperative operation model through cooperative research and development, technology procurement, and production matching, to name a few.

In the process of interenterprise cooperative innovation in the industrial park, the park management committee also plays an important role. Firstly, the management committee of the industrial park can build a cooperation platform for enterprises in the park. The management committee can acquaint themselves with the core enterprises and the smalland medium-sized enterprises' respective technological advantages and demands through fora, conferences, and the enterprise demand investigations. Then, the committee can integrate and publish information through this platform to help the enterprises inside the industrial park carry on the demand docking, which will largely increase the enterprises' cooperation opportunities in the park and promote innovation efficiency. Secondly, the park management committee can supervise and motivate the interenterprise cooperative innovation in the park. As the government's dispatch agency, the park management committee can exercise its administrative and financial powers on behalf of the government. By regularly evaluating the overall cooperative innovation performance and each main subjects' task completion degree, the management committee can implement rewards and punishments for the subjects through taxation and finance methods based on the assessment results. Therefore, this study puts forward the following assumptions.

Hypothesis 1. The game of interenterprise cooperative innovation in the park involves three main subjects, namely, the park management committee, core enterprises, and small- and medium-sized enterprises. The three parties will influence each other during the decision-making process and will finally reach the evolutionary equilibrium.

Hypothesis 2. The park management committee, core enterprises, and small- and medium-sized enterprises are bounded rationality, and they can continuously learn and modify strategies in multiple games to determine the optimal strategy.

Hypothesis 3. Due to the information asymmetry, the park management committee plays a leading role in the decisionmaking process.

2.2. Model Symbol Description. The collection of the management committee's strategies is (participate, not participate). Assuming the probability that the management committee choosing to participate in cooperative innovation is $x$, the probability that the management committee choosing not to participate in cooperative innovation is $(1-x)$; core enterprises and small- and medium-sized enterprises can also choose to participate or not participate in cooperative innovation according to their own needs, and the collection of their strategies is (cooperation, not cooperation). Assuming that the probability of core enterprises participating in cooperative innovation is $y$, the probability of core enterprises choosing not to participate in cooperative innovation is $(1-y)$; the willingness of small- and mediumsized enterprises to choose to carry out cooperative innovation is $z$, and the willingness of small- and medium-sized enterprises to choose not to carry out cooperative innovation is $(1-z)$. Moreover, $x, y, z \in[0,1]$.

Using $P_{1}$ to represent the benefits earned by the park management committee in choosing the "participation" strategy and using $b$ to indicate the percentage of the benefits earned by the management committee in choosing the "nonparticipation" strategy over the benefits earned by the committee in choosing the "participation" strategy, the benefits obtained by the committee in choosing the "nonparticipation" strategy are $b P_{1} b \in[0,1]$. We use $P_{2}$ and $P_{3}$ to represent the initial benefits of the core enterprises and small- and medium-sized enterprises before coinnovation. Cooperative innovation income refers to the extra income generated by the cooperative innovation results, which depends on the complementarity degree of the innovation resources shared by the main subjects, which are represented by $R$ and the degree of trust among the subjects involved in cooperative innovation, which is represented by $T$. Therefore, when both core enterprises and small- and mediumsized enterprises choose cooperative innovation, the benefits generated can be expressed as $R T$. If the share ratio coefficient of this part of the cooperative innovation income is $a$, the core enterprise's cooperative innovation revenue is $a R T$, and the small- and medium-sized enterprises' cooperative innovation revenue is $(1-a) R T, a, R, T \in[0,1]$. In addition, when small- and medium-sized enterprises choose to participate in cooperative innovation and core companies choose independent research and development, the income of core enterprise is $L_{1}$; when core enterprises choose cooperative innovation and small- and medium-sized enterprises choose independent research and development, the income of small- and medium-sized enterprises is $L_{2}$.

The total cost of the park management committee's supervision and incentive measures is $M_{1}$. When core enterprises and small- and medium-sized enterprises choose 
to participate in innovative activities, they must invest a certain amount of human, material, and financial resources. Then, the costs of these material and financial resources will be $C_{1}$ and $C_{2}$, respectively. When the park management committee chooses to participate in cooperative innovation, the preferential policies it provides will reduce the total cost invested by both core enterprises and small- and mediumsized enterprises in the cooperative innovation process. The reduced amount on cost will be $S$. In that case, the total cost paid by the core enterprises and the small- and mediumsized enterprises will become $\left(C_{1}+C_{2}-S\right)$.

Under the supervision of the administrative committee, if the small- and medium-sized enterprises choose cooperative innovation, but the core enterprises choose not to participate in the cooperative innovation, the core enterprises must pay the punishment to the small- and mediumsized enterprises, which can be represented by $K$. If the core enterprise chooses to carry on the cooperation innovation but the small- and medium-sized enterprises choose not to carry on the cooperation innovation, that is, the small- and medium-sized enterprises default, the small- and mediumsized enterprise must pay the punishment to the core enterprise. This amount can be represented by $W$. In addition, according to the overall performance of the cooperative innovation, the management committee will give tax reduction or financial support to the core enterprises and small- and medium-sized enterprises that actively participate in the cooperative innovation, which can be represented by $M_{2}$ and $M_{3}$, respectively.

2.3. Payment Matrix Construction. Tables 1 and 2 show the payment matrices of the three parties in the cooperative innovation game among enterprises from the perspective of the park management committee participation.

\section{Evolutionary Stability Strategy}

3.1. Construction of Return Expectation Function. According to Tables 1 and 2, when the management committee selects the "participation" strategy, its expected return can be expressed as $U_{m 1}, U_{m 2}$ can be used to describe its expected return of the "nonparticipation" strategy and the average expected return can be expressed as $\bar{U}_{m}$ :

$$
\begin{aligned}
U_{m 1} & =y z\left(P_{1}-M_{1}-M_{2}-M_{3}\right)+y(1-z)\left(P_{1}-M_{1}\right)+(1-y) z\left(P_{1}-M_{1}\right)+(1-y)(1-z)\left(P_{1}-M_{1}\right), \\
U_{m 2} & =y z b P_{1}+y(1-z) b P_{1}+(1-y) z b P_{1}+(1-y)(1-z) b P_{1}, \\
\bar{U}_{m} & =x U_{m 1}+(1-x) U_{m 2} .
\end{aligned}
$$

When the core enterprise selects the "participation" strategy, its expected return can be expressed as $U_{b 1}, U_{b 2}$ can be used to describe its expected return of the "nonparticipation" strategy, and the average expected return can be expressed as $\bar{U}_{b}$ :

$$
\begin{aligned}
U_{b 1}= & z x\left[P_{2}+a R T-t\left(\left(C_{1}+C_{2}-S\right)+M_{2}\right]\right. \\
& +(1-z) x\left(P_{2}-C_{1}+W\right) \\
& +z(1-x)\left[P_{2}+a R T-t\left(C_{1}+C_{2}\right)\right] \\
& +(1-z)(1-x)\left(P_{2}-C_{1}\right), \\
U_{b 2}= & z x\left(P_{2}+L_{1}-K\right)+(1-z) x P_{2} \\
& +z(1-x)\left(P_{2}+L_{1}\right)+(1 \\
\bar{U}_{b}= & y U_{b 1}+(1-y) U_{b 2} .
\end{aligned}
$$

When the small- and medium-sized enterprises select the "participation" strategy, their expected return can be expressed as $U_{s 1}, U_{s 2}$ can be used to describe its expected return of the "nonparticipation" strategy, and the average expected return can be expressed as $\bar{U}_{s}$ :

$$
\begin{aligned}
U_{s 1}= & x y\left[P_{3}+(1-a) R T-(1-t)\left(C_{1}+C_{2}-S\right)+M_{3}\right]+x(1-y)\left(P_{3}-C_{2}+K\right) \\
& +(1-x) y\left[P_{3}+(1-a) R T-(1-t)\left(C_{1}+C_{2}\right)\right]+(1-x)(1-y)\left(P_{3}-C_{2}\right), \\
U_{s 2}= & x y\left(P_{3}+L_{2}-W\right)+x(1-y) P_{3}+(1-x) y\left(P_{3}+L_{2}\right)+(1-x)(1-y) P_{3}, \\
\bar{U}_{s}= & z U_{s 1}+(1-z) U_{s 2} .
\end{aligned}
$$


TABLE 1: Payment matrix of interenterprise cooperative innovation game under the participation of the management committee.

\begin{tabular}{|c|c|c|c|}
\hline & & \multicolumn{2}{|c|}{ Small- and medium-sized enterprises } \\
\hline & & Cooperation $(z)$ & Noncooperation $(1-z)$ \\
\hline Core enterprise & Noncooperation $(1-y)$ & $\begin{array}{c}P_{1}-M_{1}-M_{2}-M_{3} \\
P_{2}+a R T-t\left(C_{1}+C_{2}-S\right)+M_{2} \\
P_{3}+(1-a) R T-(1-t)\left(C_{1}+C_{2}-S\right)+M_{3} \\
P_{1}-M_{1} \\
P_{2}+L_{1}-K \\
P_{3}-C_{2}+K\end{array}$ & $\begin{array}{c}P_{1}-M_{1} \\
P_{2}-C_{1}+W \\
P_{3}+L_{2}-W \\
P_{1}-M_{1} \\
P_{2} \\
P_{3}\end{array}$ \\
\hline
\end{tabular}

TABle 2: Payment matrix of interenterprise cooperative innovation game in the park without the management committee's participation.

\begin{tabular}{lcc}
\hline & \multicolumn{2}{c}{ Small- and medium-sized enterprise } \\
Noncooperation $(1-z)$
\end{tabular}

\subsection{Using Evolutionary Stability Strategy for Replicating} Dynamic Equations. Based on the analysis above, the copy dynamic equations of the management committee are as follows:

$$
\begin{aligned}
F(x) & =\frac{\mathrm{d} x}{\mathrm{~d} t}=x\left(U_{m 1}-\bar{U}_{m}\right) \\
& =x(1-x)\left[y z\left(-M_{2}-M_{3}\right)+(1-b) P_{1}-M_{1}\right] .
\end{aligned}
$$

The copy dynamic equations of the core enterprises are as follows:

$$
\begin{aligned}
F(y)= & \frac{\mathrm{d} y}{\mathrm{~d} t}=y\left(U_{b 1}-\bar{U}_{b}\right) \\
= & y(1-y)\left\{x z\left(t S+M_{2}+K-W\right)\right. \\
& \left.+x W+z\left[a R T-t\left(C_{1}+C_{2}\right)-L_{1}+C_{1}\right]-C_{1}\right\} .
\end{aligned}
$$

The copy dynamic equations of the small- and mediumsized enterprises are as follows:

$$
\begin{aligned}
F(z)= & \frac{d z}{d t}=z\left(U_{s 1}-\bar{U}_{s}\right) \\
= & z(1-z)\left\{x y(1-t) S+M_{3}+W-K\right]+x K \\
& \left.+y\left[(1-a) R T-(1-t)\left(C_{1}+C_{2}\right)-L_{2}+C_{2}\right]-C_{2}\right\} .
\end{aligned}
$$

3.3. Stability Analysis of the Equilibrium Point. Ritzberger and Weibull pointed out that the progressive stability of multi-group evolutionary games must only analyse eight equilibrium points, that is, $E_{1}(0,0,0), E_{2}(0,0,1), E_{3}(0,1,0)$, $E_{4}(0,1,1), E_{5}(1,0,0), E_{6}(1,0,1), E_{7}(1,1,0)$, and $E_{8}(1,1,1)$. The following takes $E_{1}(0,0,0)$ as an example for analysis [36].

According to the method proposed by Friedman, the equilibrium point can be analysed by the Jacobian matrix [37]. At $E_{1}$, the Jacobian matrix of the system is given by

$$
J_{1}=\left[\begin{array}{ccc}
(1-b) P_{1}-M_{1} & 0 & 0 \\
0 & -C_{1} & 0 \\
0 & 0 & -C_{2}
\end{array}\right] .
$$

Obviously, the three characteristic roots of the matrix are $\lambda_{1}=(1-b) P_{1}-M_{1}, \lambda_{2}=-C_{1}$, and $\lambda_{3}=-C_{2}$. If $\lambda_{1}, \lambda_{2}, \lambda_{3}$ are all less than 0 , then, $E_{1}(0,0,0)$ will be a potential stable point. Put differently, the system is likely to reach a status, in which no party participates in cooperative innovation. By analogy, we can obtain the characteristics of the Jacobian matrix of each equilibrium point. The analytical analysis indicates that only $E_{3}$ $(0,0,1)$ and $E_{4}(0,1,0)$ are definitely the unstable points of the system as the characteristics of the Jacobian of the two points are all less than 0 in any case. Yet, we cannot clarify the status of the remaining six points as eigenvalues could be either positive or negative. We cannot further clarify the status of the six points unless we make more assumptions on ranges or bounds or relationships between parameters. Such process is complex and difficult to conduct solutions, which is also the shortcoming of the analytical strategy. In fact, these unknown points also mean that there exist various possible outcomes of the game. In this way, we adopt the numerical analysis approach to further process our study to obtain more valuable insights in the following section. 


\section{Numerical Analysis of Interenterprise Cooperative Innovation in the Industrial Park}

In addition, in order to match the parameter setting with the actual situation, we investigated at Shanghai Zhangjiang HiTech Industry Alliance Center to collect data of cooperation innovation situation, when part of the data is not available, the parameters are estimated based on the advice of experts (Table 3). As a result, the following assumptions are given for the initial values of the parameters in the payment matrix. The unit is million yuan. The benefit of the management committee for participating in cooperative innovation $P_{1}=100$; the management committee's policy and monitoring costs $M_{1}=20$; the management committee's financial support for core enterprises $M_{2}=30$; and the financial support for small- and medium-sized enterprises $M_{3}=15$. The cost of innovation activities of core enterprises $C_{1}=60$, the cost of innovation activities of small- and medium-sized enterprises $C_{2}=25$, the cost-sharing ratio of core enterprises and small- and medium-sized enterprises in cooperative innovation $t=0.8$; the complementarity of resources between core enterprises and small- and medium-sized enterprises $R=10$; trust level $T=10$, cooperation innovation revenue is $R T=100$, and sharing ratio of cooperation innovation revenue $a=0.75$. The proportion of revenue obtained by the management committee when it chooses not to participate in cooperative innovation is $b=0.3$. The benefits when core enterprises and small- and medium-sized enterprises choose to conduct innovation individually are $L_{1}=70$ and $L_{2}=10$, respectively. The penalties for core enterprises and small- and medium-sized enterprises are $K=20$ and $W=5$, respectively.

On the basis of the above analysis and the setting of initial values, this study uses Matlab software to simulate the dynamic evolution process of the strategy selection of the industrial park management committee, core enterprises, and small- and medium-sized enterprises under different initial conditions. Besides, although the above set parameters can reflect the actual conditions of the case industrial park, different parks may vary in these parameters. Thus, the possible outcomes of the game vary in different settings. In this way, we also adjust these parameters to break out the various possible outcomes of the game. In line with the results of the simulation analysis, the initial participation willingness of the three main subjects, the preferential policies put forward by the management committee, the punishment strength, and the revenue distribution coefficient are discussed.

4.1. Effect of Initial Willingness on the Evolution of Cooperative Innovation Relationships. Figure 1 simulates the effect of changes in the initial willingness of the management committee, core enterprises, and small- and medium-sized enterprises to participate in cooperative innovation with other parameters unchanged. Assuming that the initial willingness of the management committee, the core enterprise, and the small- and medium-sized enterprises to participate in the cooperative innovation is the same, which means $x=y=z$. As shown in Figure 1, the critical values of the initial willingness of the three parties are between 0.6 and 0.7. If the initial willingness of $x, y, z$ is smaller than this critical value, $x$ will converge to $1, y, z$ will converge to 0 , and the final equilibrium point will tend to be $(1,0,0)$. If the initial willingness of $x, y, z$ is all larger than the critical value, $x, y, z$ will all converge to 1 , and the final equilibrium point will tend to be $(1,1,1)$. Thus, with the increase in the management committees' willingness to participate in cooperative innovation, the intention of small- and medium-sized enterprises not to participate in cooperative innovation has been considerably suppressed, whereas the core enterprises are relatively less affected. When the participation willingness of the management committee is very strong, the participation willingness of the core enterprises and smalland medium-sized enterprises has also increased substantially, and ultimately, all three parties choose to participate in cooperative innovation. The simulation results show that with the initial intention of $x, y, z$ to keep increasing, the three parties tend to participate in cooperative innovation in the end. This finding is explained by the fact that in the interenterprise cooperative innovation, if the willingness of core enterprises and small- and medium-sized enterprises to participate in cooperative innovation is not very strong, the park management committee will immediately play its leading role by setting up cooperative innovation platforms, establishing resources and information exchange channels, perfecting the cooperative innovation operation mechanism and promoting the core enterprises and small- and mediumsized enterprises' cooperation willingness.

Figure 2 simulates the effect of changes in the initial participation willingness of the management committee $x$ on the core enterprises and small- and medium-sized enterprises' choice of cooperative innovation strategies with other parameters unchanged. As can be seen from Figure 2, the initial participation willingness of the core enterprises and small- and medium-sized enterprises remains unchanged. With the increasing willingness of the management committee to participate in the cooperative innovation, the intention of the core enterprises and the small- and mediumsized enterprises not to cooperate is obviously restrained, and the changing speed of small- and medium-sized enterprises is faster than that of core enterprises. This finding is explained by the fact that during cooperative innovation, small- and medium-sized enterprises are in a disadvantaged position and must therefore obtain corresponding resources through the platform and communication channels established by the management committee. Accordingly, the participation willingness of the management committee has a huge impact on it. By contrast, the core enterprises have a strong resource base and other channels to obtain resources and therefore rely less on the management committee. Thus, the participation willingness of the management committee has a relatively small impact on it.

Figure 3 simulates the influence of the change in the initial participation willingness of the core enterprise on the choice of management committee and the small- and medium-sized enterprises' cooperative innovation strategy with 
TABle 3: Model parameters' plausible ranges.

\begin{tabular}{|c|c|c|}
\hline Parameters & Description & $\begin{array}{c}\text { Plausible } \\
\text { ranges }\end{array}$ \\
\hline$P_{1}$ & The benefits earned by the park management committee when they participate in cooperation innovation & $95 \sim 105$ \\
\hline$b$ & $\begin{array}{l}\text { The percentage of the benefits earned by the management committee in choosing the "nonparticipation" } \\
\text { strategy over "participation" strategy }\end{array}$ & $0.28 \sim 0.32$ \\
\hline$R$ & The complementarity degree of the innovation resources shared by the main subjects & $10 \sim 11$ \\
\hline$T$ & The degree of trust among the subjects & $10 \sim 11$ \\
\hline$a$ & The share ratio coefficient of cooperative innovation income & $0.75 \sim 0.85$ \\
\hline$L_{1}$ & The innovation income of core enterprises when they choose not to participate in cooperation & $66 \sim 74$ \\
\hline$L_{2}$ & The innovation income of SMEs when they choose not to participate in cooperation & $8 \sim 12$ \\
\hline$M_{1}$ & The total cost of the park management committee's supervision and incentive measures & $15 \sim 25$ \\
\hline$C_{1}$ & The initial innovation cost of core enterprises & $57 \sim 63$ \\
\hline $\mathrm{C}_{2}$ & The initial innovation cost of SMEs & $23 \sim 27$ \\
\hline$S$ & The reduced amount on cost provided by the park management committee & $22 \sim 26$ \\
\hline$K$ & The fine core enterprises need to pay & $20 \sim 24$ \\
\hline$W$ & The fine SMEs need to pay & $10 \sim 14$ \\
\hline$M_{2}$ & The subsidy to core enterprises provided by the park management committee & $15-34$ \\
\hline$M_{3}$ & The subsidy to SMEs provided by the park management committee & $15 \sim 19$ \\
\hline
\end{tabular}

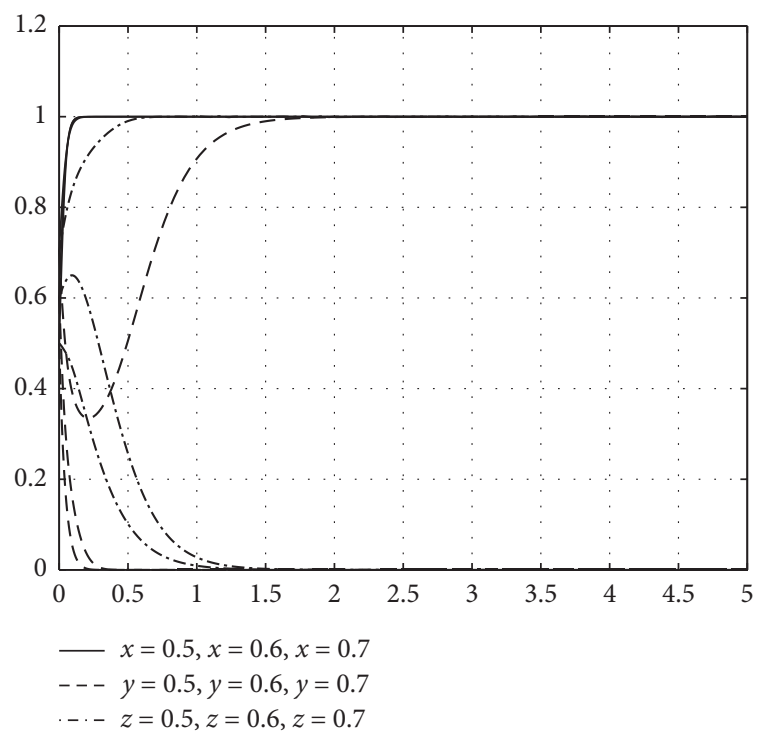

FIGURE 1: Evolution results of simultaneous changes in participation willingness of $x, y, z$.

other parameters unchanged. As seen from Figure 3, the management committee and the small- and medium-sized enterprises' initial willingness to participate in the cooperative innovation $x, z$ remain unchanged. With the increase in $y$ which denotes the willingness of the core enterprises to participate in the cooperative innovation, the willingness of the small- and medium-sized enterprises to participate in the cooperative innovation has been obviously improved, and the range of changes is obviously larger than that of the core enterprises.

Figure 4 simulates the impact of changes in the initial participation willingness of small- and medium-sized enterprises $z$ on the choice of management committee and core enterprises' participation strategies with other parameters unchanged. From Figure 4, the initial participation willingness of the management committee $x$ and core enterprises $y$ remains unchanged. As the willingness of small- and

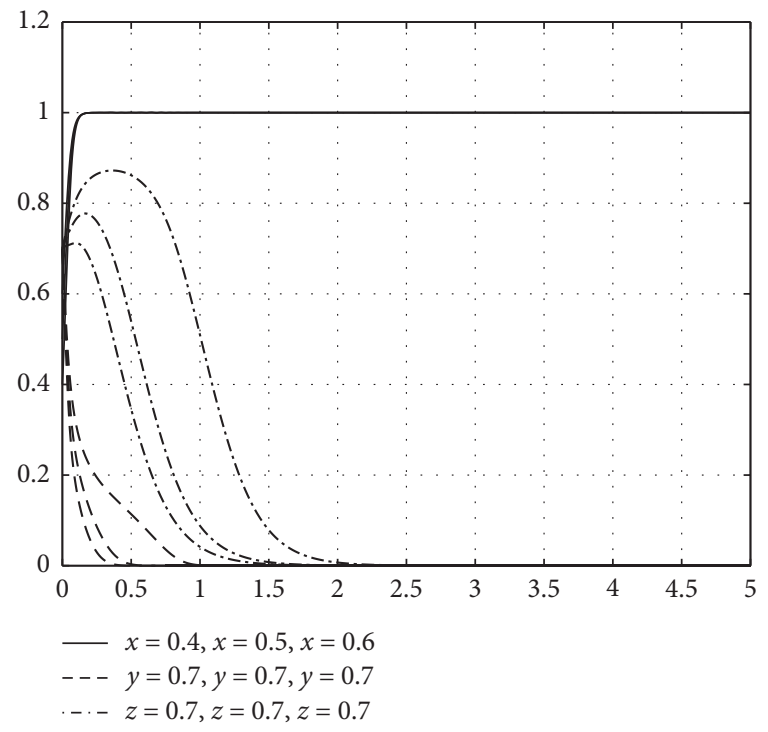

FIGURE 2: Evolution results of changes in participation willingness $x$.

medium-sized enterprises to participate in cooperative innovation $z$ increases, the willingness of core enterprises to participate in cooperative innovation also increases. However, its change range is smaller than that of the small- and medium-sized enterprises.

The simulation results of Figures 3 and 4 show that the participation willingness of the core enterprises and the small- and medium-sized enterprises significantly affects each other. The increase in one party's initial participation willingness will lead to the promotion of the other party's participation willingness. In addition, small- and mediumsized enterprises are sensitive to the changes in the core enterprises' participation willingness, that is, the participation strategies of the small- and medium-sized enterprises are likely affected by the changes in the participation willingness of core enterprises. This finding is due to the unequal positions between small- and medium-sized enterprises and 


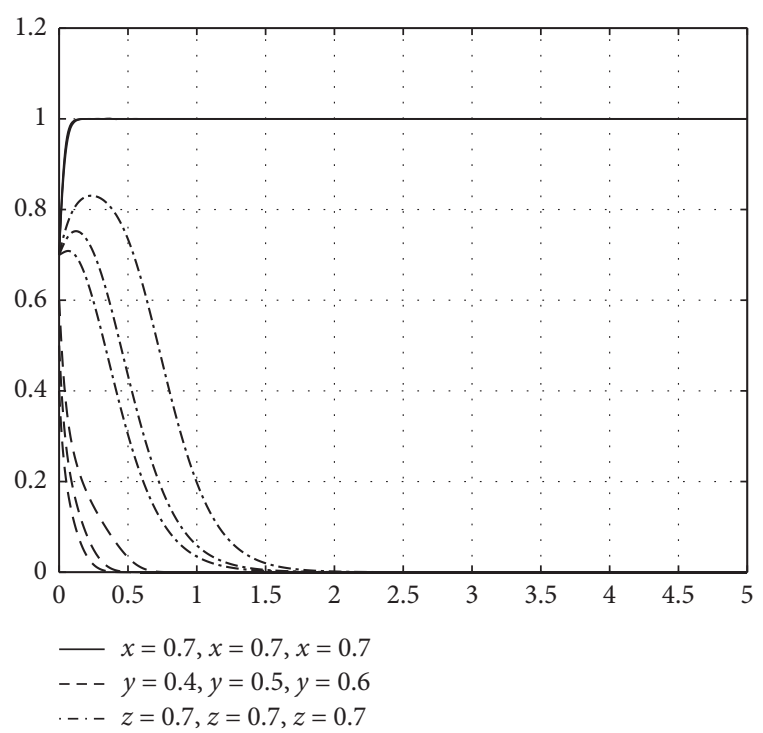

FigUre 3: Evolution results of changes in participation willingness $y$.

core companies in this cooperative innovation relationship. Compared with small- and medium-sized enterprises, core enterprises hold more scarce resources and occupy the dominant position. Therefore, when the willingness of the core enterprises to participate in cooperation increases, the willingness of the small- and medium-sized enterprises to cooperate will naturally increase. By contrast, although the willingness of small- and medium-sized enterprises to cooperate is extremely large, it can only cause minor changes in the willingness of core enterprises to cooperate.

The simulation results in Figure 5 show that with other parameters unchanged, when the initial participation willingness of the core enterprises $y$ and small- and mediumsized enterprises $z$ is high, even if the initial willingness of the management committee $x$ is low, $y, z$ will converge to 1 , that is, core enterprises and small- and medium-sized enterprises will eventually choose to participate in cooperative innovation. By contrast, when the initial participation willingness of core enterprises $y$ and small- and mediumsized enterprises $z$ is low, even if the initial willingness of the management committee $x$ is high, $y$ and $z$ will converge to 0 , that is, the core enterprises and small- and medium-sized enterprises will choose not to participate in cooperative innovation. Moreover, the figure shows that when core enterprises and small- and medium-sized enterprises choose not to participate in cooperative innovation, the speed of $y$ convergence to 0 is obviously higher than that of $z$. The simulation results show that when the benefits of cooperative innovation are insufficient to meet the psychological expectations of the enterprise, and the incentives given by the management committee are insufficiently strong, the effect of the management committee's choice of participation strategy on core enterprises and small- and mediumsized enterprises will be immaterial, and market orientation will become the key factor affecting their strategic choices. Moreover, the small- and medium-sized enterprises will be more affected by the participation of the management

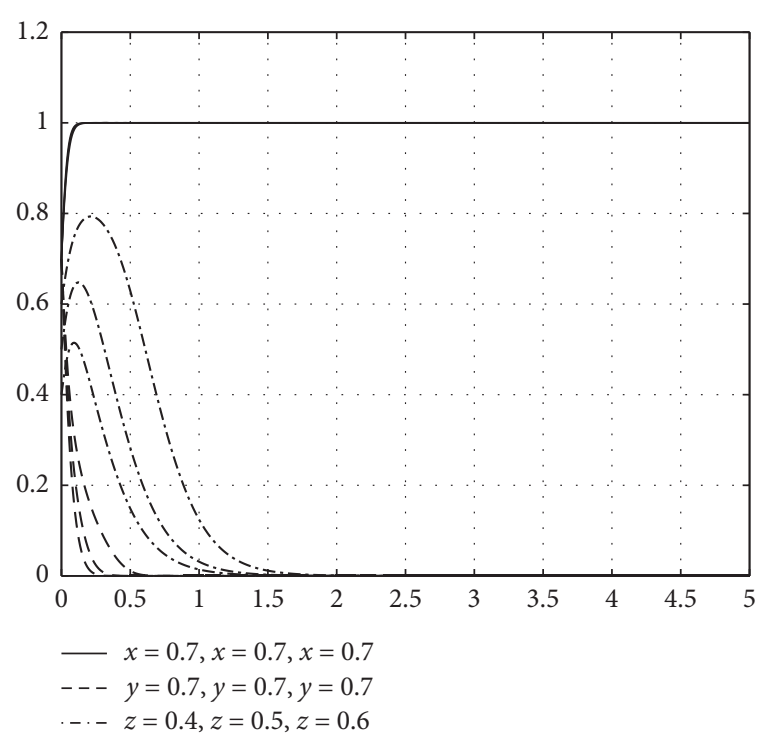

FIGURE 4: Evolution results of changes in participation willingness $z$.

committee than the core enterprises. Conversely, if the cooperative innovation can bring sufficiently large benefits to the core enterprises and small- and medium-sized enterprises, even if the support provided by the management committee is relatively small, the willingness of the enterprises of core enterprises and small- and medium-sized enterprises to participate in the cooperative innovation will still be strong, and they will eventually choose to participate in the cooperative innovation.

4.2. Effect of the Management Committee's Policy Support and Financial Support on the Evolution of Cooperative Innovation Relationships. The willingness of the park management committee to participate in cooperative innovation is reflected in two aspects. The first is policy support, which refers to the preferential policies established by the management committee which can promote cooperative innovation among enterprises within the industrial park by reducing the total cost and the innovation result transformation risk. Those preferential policies include tax incentives, transformation of innovation results, and internal procurement within the industrial park. The second is fund award, which refers to directly rewarding funds for enterprises that actively participate in cooperative innovation on the basis of performance appraisal.

Figure 6 simulates the effect of the change in the cooperative innovation cost reduction $S$, resulting from policy support provided by the management committee on the core enterprises and small- and medium-sized enterprises' choice of cooperative strategy when other parameters are unchanged. From Figure 6, the increase in $S$ accelerates the speed of $y$ and $z$ converging to 1 , and the equilibrium point tends to $(1,1,1)$. Thus, a strong policy support of the management committee also strengthens the willingness of core enterprises and small- and medium-sized enterprises to participate in cooperative innovation and finally reach cooperation. At the same time, when the increase in $S$ is 


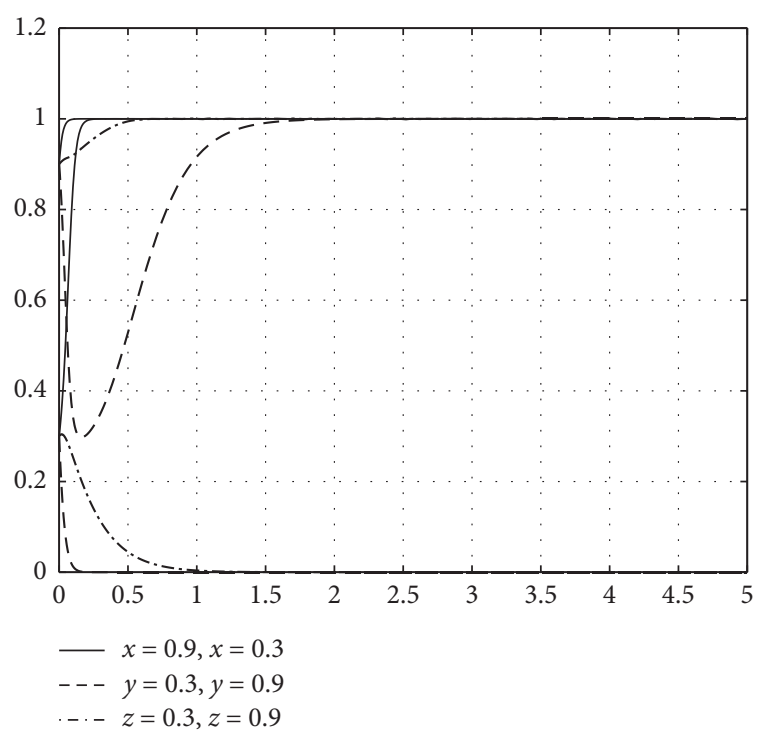

FIGURE 5: Evolution results of simultaneous participation willingness on $y, z$.

relatively small, the willingness of core enterprises to participate in cooperative innovation will initially decline. However, with the continuing increase in the management committee and the small- and medium-sized enterprises' willingness to participate in the cooperative innovation, the willingness of the core enterprises to participate in the cooperative innovation will also begin to rise. Ultimately, the cooperative strategy will be chosen. The simulation results show that the change in policy support has a significant influence on the selection of the final strategy of core enterprises and small- and medium-sized enterprises. This finding is explained by the fact that the tax reduction and exemption resulting from the policy support provided by the management committee can directly reduce the innovation costs of core enterprises and small- and medium-sized enterprises. Cooperative innovation parties only need to invest less to obtain substantial returns. Therefore, both core enterprises and small- and medium-sized enterprises will choose to participate in cooperative innovation.

Figure 7 simulates the effect of the change in the management committee's financial subsidy to the core enterprise $M_{2}$ on the choice of the core enterprise and the small- and medium-sized enterprises' participation strategy in cooperative innovation under the condition that the other parameters remain unchanged. As seen from Figure 7, the increase in $M_{2}$ hastens the convergence speed of $y, z$ to 1 , and the final equilibrium point tends to $(1,1,1)$. The simulation result shows that the increase in the subsidy fund $M_{2}$ for the core enterprises will affect the strategy choice of the core enterprises and the small- and medium-sized enterprises, and the degree of the impact on the core enterprises is greater than that of the small- and medium-sized enterprises. This finding is explained by the fact that this part of the award is a direct reward for the core enterprise provided by the management committee, and the core enterprise's participation in collaborative innovation aims to reduce the

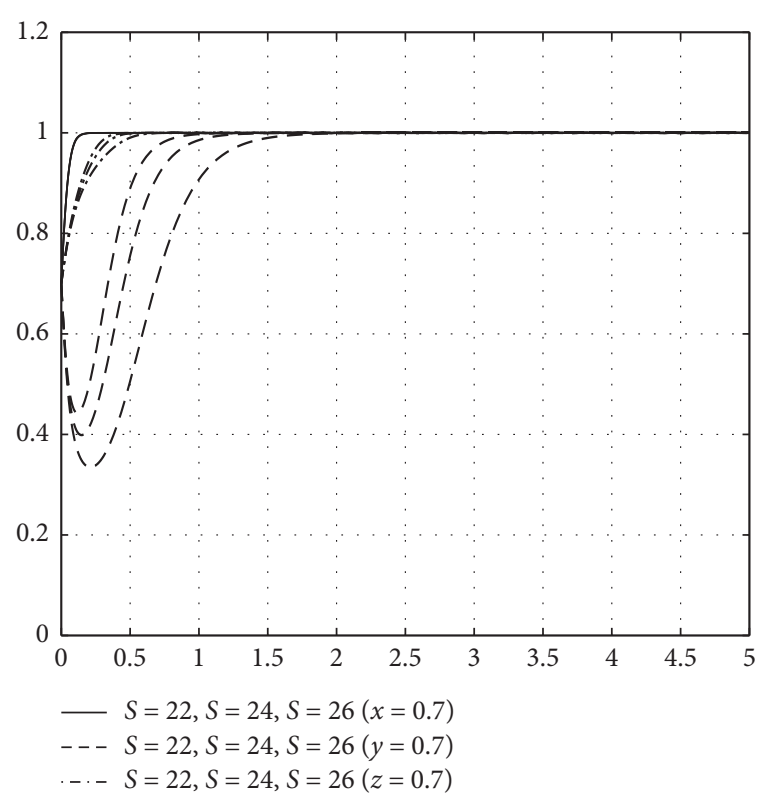

FIGURE 6: Evolution results of changes in the policy support of the management committee.

cost of innovation and increase the benefits. Therefore, the core enterprise is sensitive to the financial support provided by the management committee.

Figure 8 simulates the impact of changes in the park management committee's funding subsidy to the small- and medium-sized enterprises $M_{3}$ on the choice of core enterprises and small- and medium-sized enterprises' participation strategies in cooperative innovation with other parameters unchanged. As seen from Figure 8, the increase in $M_{3}$ has no significant influence on the choice of core enterprises and small- and medium-sized enterprises' participation strategy in cooperative innovation.

With reference to Figures 7 and 8, for small- and medium-sized enterprises, the impact of the policy support provided by the management committee on its choice of cooperative innovation strategy is greater than the funding support because small- and medium-sized enterprises have a poor antirisk capability. Accordingly, they will pay extra attention to the policy support behaviours of the management committee, such as tax reduction and exemptions, transformation of innovation results, and internal procurement within the park, which can reduce the failure rate of innovation and lower the risk of new product sales. Therefore, the policy support of the management committee has a profound effect on small- and medium-sized enterprises.

\subsection{Effect of the Penalty of the Management Committee on the} Evolution of Cooperative Innovation Relationships. Figure 9 simulates the effect of changes in the default penalty $K$, paid by core enterprises to small- and medium-sized enterprises, on the choice of core enterprises and small- and medium-sized enterprises in cooperative innovation strategies with other parameters unchanged. As seen from 


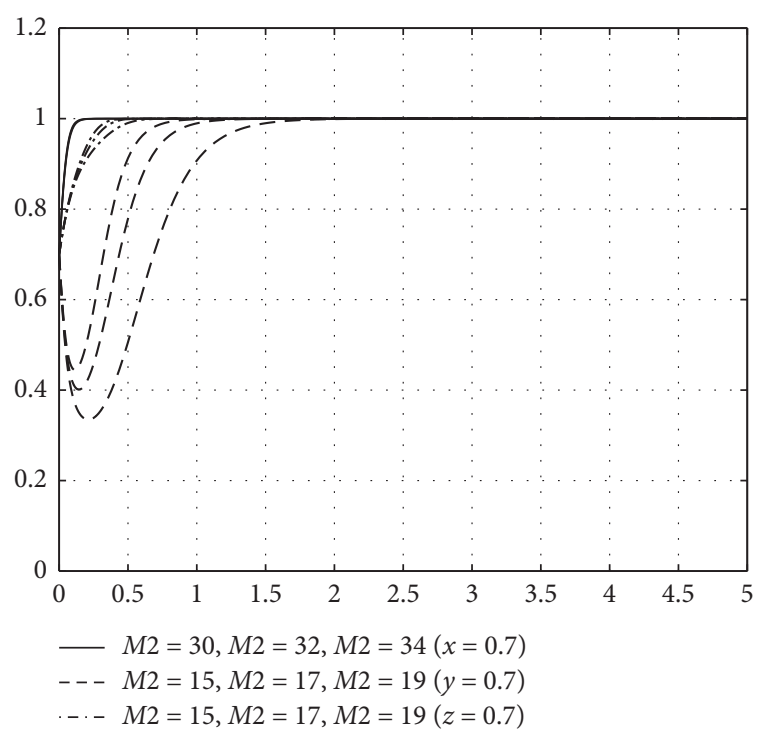

FIGURE 7: Evolution results of changes in funding support for core companies.

Figure 9, the increase in the penalty $K$ increases the speed in convergence of $y, z$ towards 1 , and the equilibrium point tends to $(1,1,1)$. With the change in $K$, the change in core enterprises' willingness to participate in cooperation is highly significant, which indicates that core enterprises are sensitive to the change in $K$.

Figure 10 simulates the effect of change in the default penalty $W$, paid by small- and medium-sized enterprises to core enterprises, on the cooperative innovation strategy of core enterprises and small- and medium-sized enterprises in the case of other parameters unchanged. As seen from Figure 10, the increase in the penalty $W$ has no significant influence on the willingness of core enterprises and smalland medium-sized enterprises to participate in cooperative innovation.

With reference to Figures 9 and 10, compared with small- and medium-sized enterprises, core enterprises are more sensitive to punishment, and larger penalties can significantly enhance their willingness to participate in cooperative innovation. This finding is explained by the fact that the goal of core enterprises participating in cooperative innovation is to maximise profit. Once they feel such pursuit as unfavourable to themselves, the willingness to participate will change immediately.

4.4. Effect of Income Distribution Coefficient on the Evolution of Cooperative Innovation Relationships. Figure 11 simulates the effect of changes in $a$, the distribution coefficient of cooperative innovation revenues of core enterprises, and small- and medium-sized enterprises on cooperative innovation strategies with other parameters unchanged. As seen from Figure 11, compared with the participation willingness of small- and medium-sized enterprises $x$, the willingness of core enterprises to participate in cooperative innovation $y$ is more sensitive to the change in benefit distribution coefficient $a$. Simulation results show that changes in the income

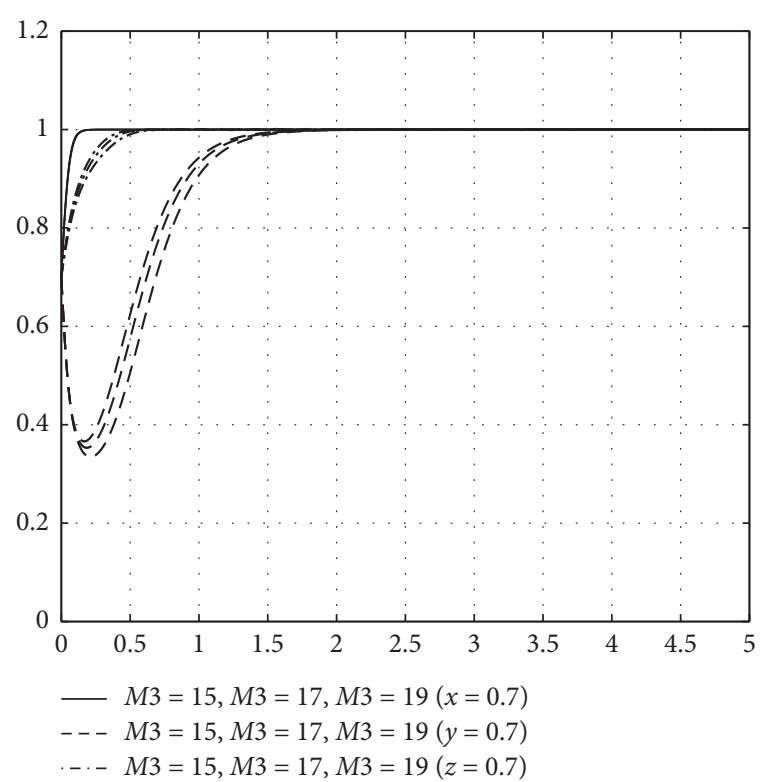

FIGURE 8: Evolution results of changes in financial support for SMEs.

distribution coefficient $a$ will affect the final strategy choices of core enterprises and small- and medium-sized enterprises, and core enterprises are sensitive to the distribution of income. Core companies pursue maximum profits in the process of cooperative innovation. Thus, they are affected by the distribution coefficient. However, the small- and medium-sized enterprises must rely on the innovation resources of the core enterprises. Thus, the bargaining power is relatively small, and the benefit distribution coefficient has a relatively small influence on the cooperation innovation intention of the small- and medium-sized enterprises.

\subsection{Impact of Complementary Resources and Trust on the} Evolution of Cooperative Innovation Relationships. Figures 12 and 13 simulate the impact of changes in the degree of complementarity of resources $R$ and the level of trust $T$ of core enterprises and small- and medium-sized enterprises on cooperative innovation strategies with other parameters unchanged. As seen from Figures 12 and 13, the degree of resource complementarity and trust between enterprises has a significant effect on the willingness of enterprises to participate in cooperative innovation. As the degree of resource complementarity $R$ and trust $T$ among enterprises increases, the degree of willingness of small- and medium-sized and core enterprises to participate in cooperation accelerates its convergence to 1 , and the ultimate equilibrium point tends to $(1,1,1)$. In addition, the changing range of core companies is large. The simulation results show that the degree of resource complementarity and trust among enterprises has a significant influence on the willingness of enterprises to participate in cooperative innovation. A strong degree of resource complementarity and trust increases the likelihood of enterprises to participate in cooperative innovation, and the core enterprises are sensitive to the degree of resource complementarity and trust. 


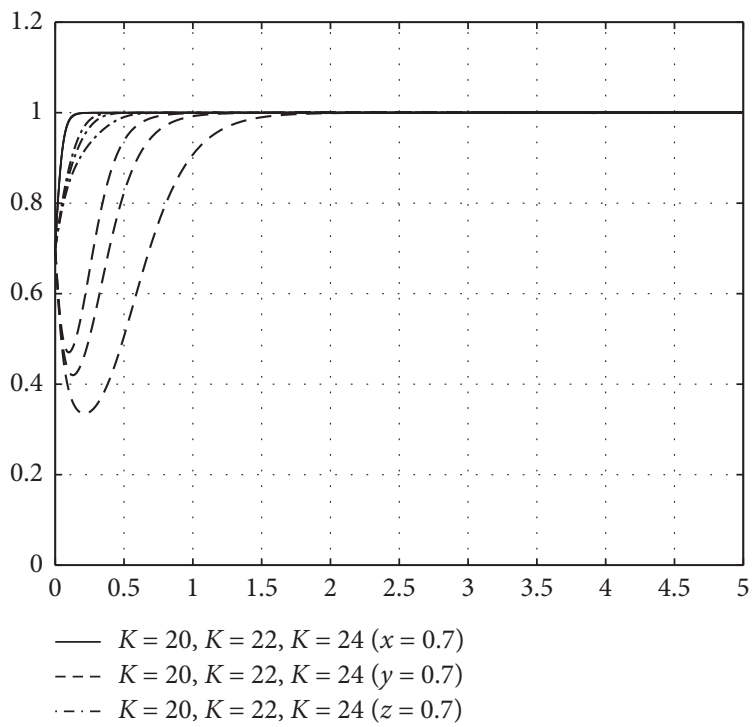

Figure 9: Evolution results of changes in penalties of core companies.

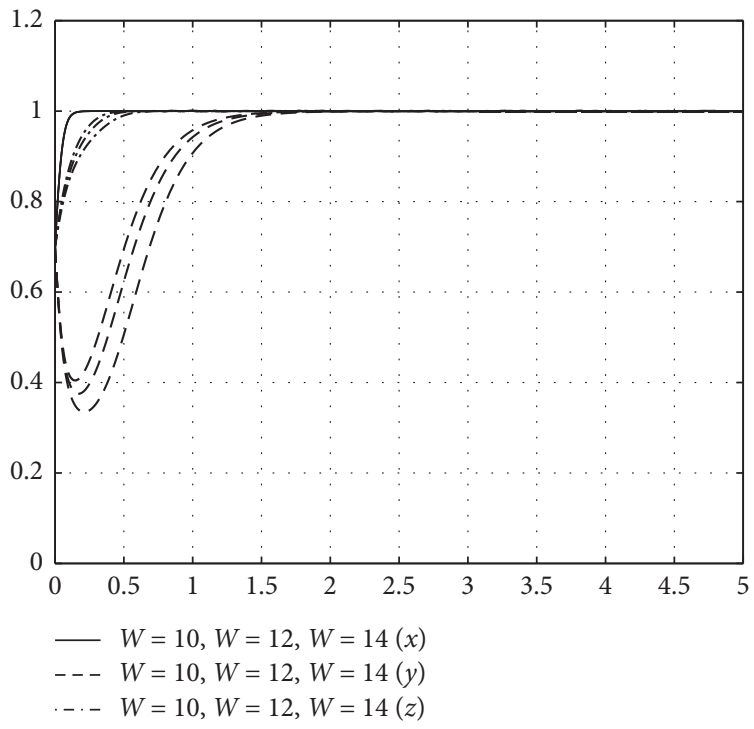

FIGURE 10: Evolution results of changes in penalties for SMEs.

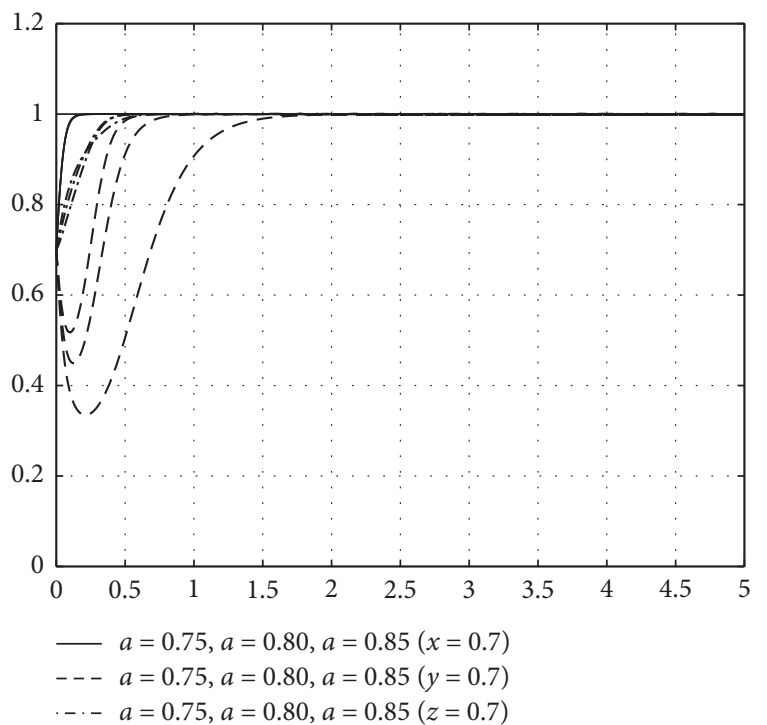

Figure 11: Evolution of the income distribution coefficient change. 


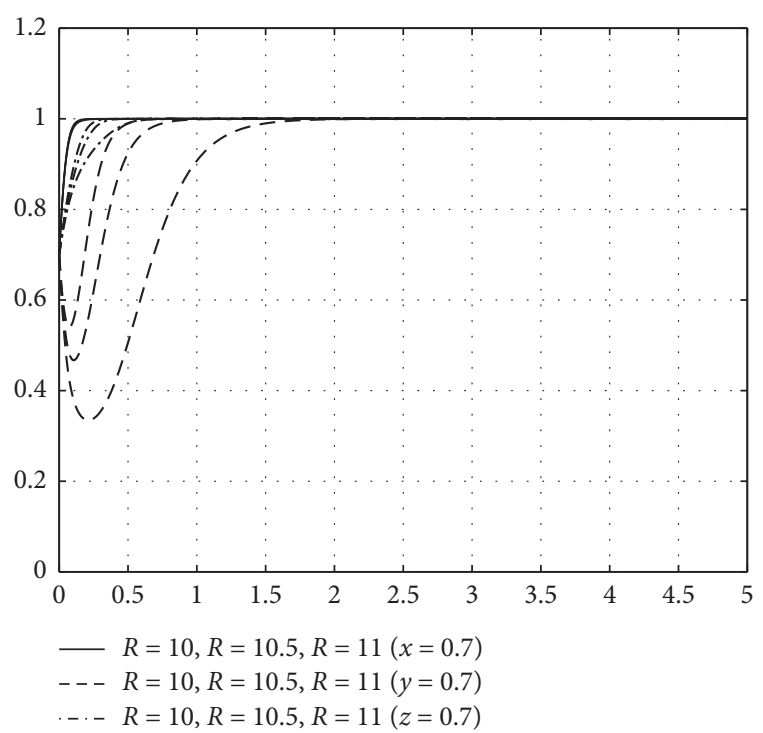

FIGURE 12: Evolution results of resource complementation changes.

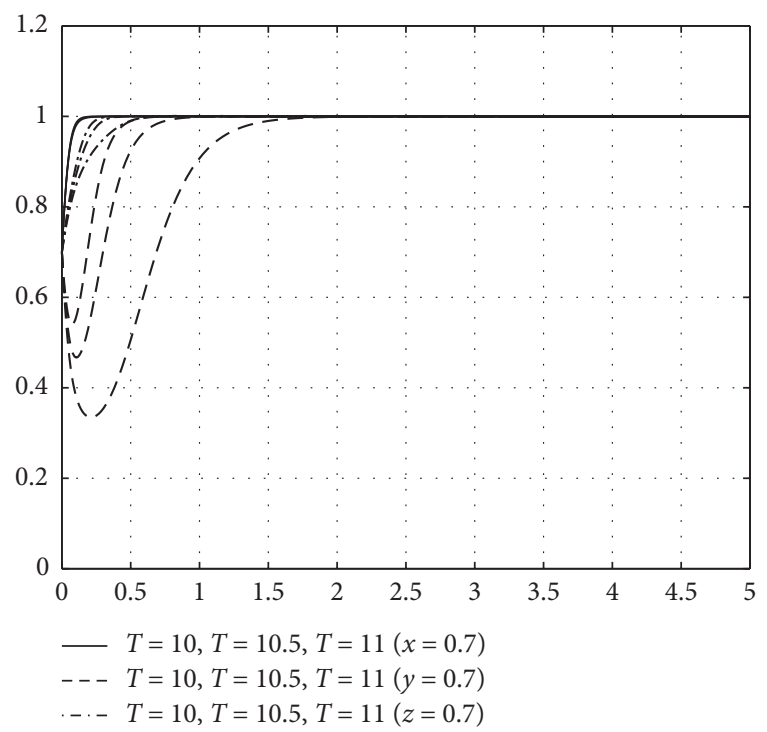

FIGURE 13: Evolution results of changes in trust.

\section{Conclusion}

On the basis of the bounded rationality of the game players, this study uses evolutionary game theory to establish a cooperative innovation game payment matrix under the supervision of the park management committee, leadership of core enterprises, and with the participation of the smalland medium-sized enterprises. It also systematically analyses the decision-making evolution process of the park management committee, the core enterprises, and the small- and medium-sized enterprises for the cooperative innovation. It combines numerical analysis to examine the behaviour of the park management committee, core enterprises, and small- and medium-sized enterprises' cooperative innovation strategies and the influencing factors. The following conclusions are drawn.
The park management committee, core enterprises, and small- and medium-sized enterprises have different degrees of influence on each other's willingness to participate in cooperative innovation. Firstly, the influence of the park management committee on core enterprises and small- and medium-sized enterprises is asymmetric. The increased willingness of the park management committee to participate in cooperative innovation can substantially improve the participation willingness of core enterprises and small- and medium-sized enterprises. However, compared with the core enterprises, the small- and medium-sized enterprises are more likely to be affected by the change in the park management committee's cooperation willingness. Secondly, the influence of core enterprises and small- and medium-sized enterprises on each other is asymmetric, and small- and medium-sized enterprises are more sensitive to the changes in the core enterprises' willingness to participate in cooperative innovation. Therefore, the park management committee should actively participate in the guidance of cooperative innovation. The work of the management committee should simultaneously focus on how to mobilise the passion of core enterprises to participate in cooperative innovation.

Small- and medium-sized enterprises are sensitive to the management committee's policy support, and core enterprises are sensitive to the management committee's financial support. The reasonable guidance of the industrial park management committee for the cooperative innovation of enterprises in the park is reflected in policy and financial support. Policy support such as innovation result transformation, tax preference, and government purchase can reduce the innovation cost and decrease the new products' sales risk. Therefore, such provision is highly important for small- and medium-sized enterprises with poor risk resistance. By contrast, core companies' participation in cooperative innovation aims to reduce their own research and development costs and improve corporate profits. Thus, direct financial support has also attracted other core enterprises to participate in cooperative innovation. Therefore, the management committee should formulate diversified guidance for the core enterprises and small- and mediumsized enterprises and establish different preferential policies to encourage both types of enterprises.

Core enterprises are more sensitive to penalties and income distribution than small- and medium-sized enterprises. The main appeal of core enterprises to participate in cooperative innovation is to reduce innovation costs and pursue maximum economic benefits. Therefore, changes in penalties and income distribution will cause rapid changes in their willingness to participate in cooperative innovation. Consequently, appropriately increasing the punishment of core enterprises and guiding core enterprises to participate in cooperative innovation through negative incentives are necessary. A reasonable income distribution mechanism should be also be formulated to enhance the enthusiasm of core enterprises for cooperative innovation through positive incentives.

The degree of resource complementarity and trust among enterprises has a profound effect on core enterprises and small- and medium-sized enterprises' willingness to 
participate in cooperative innovation. A high degree of complementarity of resources and trust level between enterprises strengthens the willingness of both types of enterprises to choose to participate in cooperative innovation. Therefore, the management committee must pay attention to investigate the needs of enterprises inside the industrial park to improve the degree of resource matching between enterprises. Enhancing mutual trust between enterprises is possible through various approaches such as fora, communication meetings, and supervision of the cooperative innovation process. Consequently, the willingness of core enterprises and small- and medium-sized enterprises to participate in cooperative innovation will also increase.

As a local economic carrier, China's industrial parks have failed to effectively play their leading role in promoting industrial transformation and upgrading. The reason lies in the low degree of industrial agglomeration inside of the park. Therefore, it is urgent to strengthen the innovation cooperation among enterprises inside of park to accelerate the industrial linkage and upgrading. However, due to the lack of communication channels and mutual trust, it is difficult to establish $\mathrm{R} \& \mathrm{D}$ cooperation among enterprises. Therefore, it is essential for the park management committee to play a leading role and build a cooperation platform to promote cooperation among enterprises in the park. The three-party game model and simulation results indicate that the behavior of the park management committee has a strong guiding effect on the behavior choice of the core enterprises and smalland medium-sized enterprises in the park. Meanwhile, the effect of different policies on the core enterprises and smalland medium-sized enterprises varies. Therefore, the management committee needs to identify effective policies and implement differentiated incentives and supervision measures for different types of enterprises. The findings of this research can provide effective practical guidance for industrial park managers in China. However, there are still some defects and shortcomings in this research. Firstly, even though this study collected data from the real case, but this research only investigated in one industrial park, and some data are unavailable, so the universality of the research conclusions needs to be improved. Secondly, the variable design in this study is based on the assumptions of common scenarios, and it is inevitable that there are other variables that are not taken into account. In fact, the innovation cooperation among enterprises inside of the industrial park is more complex, including other participants, such as university and research institutions and intermediary service institutions, which is also the direction of further research in this paper.

\section{Data Availability}

The data used to support the findings of this study are available from the corresponding author upon request.

\section{Conflicts of Interest}

The authors declare there are no conflicts of interest regarding the publication of this paper.

\section{Acknowledgments}

This research was funded by the National Social Science Found of China (grant no. 17BGL099) and the Humanities and Social Sciences Foundation of the Ministry of Education of China (Grant no. 19C10276025).

\section{References}

[1] Q. Wang, R. Yang, R. Zhao, and C. Wang, "Does state-level upgrade of high-tech zones promote urban innovation efficiency: evidence from China," Sustainability, vol. 11, no. 21, p. 6071, 2019.

[2] J. Wang, "The economic impact of special economic zones: evidence from Chinese municipalities," Journal of Development Economics, vol. 101, pp. 133-147, 2013.

[3] D. Z. Zeng, How Do Special Economic Zones and Industrial Clusters Drive China's Rapid Development?, The World Bank, Washington, DC, USA, 2011.

[4] Y. Geng and Z. Hengxin, "Industrial park management in the Chinese environment," Journal of Cleaner Production, vol. 17, no. 14, pp. 1289-1294, 2009.

[5] K. Xie, Y. Song, W. Zhang, J. Hao, Z. Liu, and Y. Chen, "Technological entrepreneurship in science parks: a case study of Wuhan Donghu High-Tech Zone," Technological Forecasting and Social Change, vol. 135, pp. 156-168, 2018.

[6] L. Lingji, H. Ping, and Z. Lei, "Roles, models and development trends of hi-tech industrial development zones in China," International Journal of Technology Management, vol. 28, no. 3-6, pp. 633-645, 2004.

[7] S. Chung, "Building a national innovation system through regional innovation systems," Technovation, vol. 22, no. 8, pp. 485-491, 2002.

[8] J. F. Ye, H. Ren, and J. Zhen, "Theme and evolution of threedecade development polices of national industrial park in China," Scientific Research, vol. 33, no. 11, pp. 1634-1640, 2015, in Chinese.

[9] C. He, "Foreign manufacturing investment in China: the role of industrial agglomeration and industrial linkages," China \& World Economy, vol. 16, no. 1, pp. 82-99, 2008.

[10] P.-P. Combes, G. Duranton, and L. Gobillon, "The identification of agglomeration economies," Journal of Economic Geography, vol. 11, no. 2, pp. 253-266, 2011.

[11] H. Yoon, S. Yun, J. Lee, and F. Phillips, "Entrepreneurship in East Asian regional innovation systems: role of social capital," Technological Forecasting and Social Change, vol. 100, pp. 83-95, 2015.

[12] D. Urbano and S. Aparicio, "Entrepreneurship capital types and economic growth: international evidence," Technological Forecasting and Social Change, vol. 102, pp. 34-44, 2016.

[13] A. K. W. Lau and W. Lo, "Regional innovation system, absorptive capacity and innovation performance: an empirical study," Technological Forecasting and Social Change, vol. 92, pp. 99-114, 2015.

[14] N. Sachdeva, P. K. Kapur, and O. Singh, "An innovation diffusion model for consumer durables with three parameters," Journal of Management Analytics, vol. 3, no. 3, pp. 240-265, 2016.

[15] S. S. Levine and M. J. Prietula, "Open collaboration for innovation: principles and performance," Organization Science, vol. 25, no. 5, pp. 1414-1433, 2014.

[16] C. Andriopoulos and M. W. Lewis, "Exploitation-exploration tensions and organizational ambidexterity: managing 
paradoxes of innovation," Organization Science, vol. 20, no. 4, pp. 696-717, 2009.

[17] A. Spithoven, W. Vanhaverbeke, and N. Roijakkers, "Open innovation practices in SMEs and large enterprises," Small Business Economics, vol. 41, no. 3, pp. 537-562, 2013.

[18] S. A. Zahra and G. George, "Absorptive capacity: a review, reconceptualization, and extension," The Academy of Management Review, vol. 27, no. 2, pp. 185-203, 2002.

[19] X. Li, "Sources of external technology, absorptive capacity, and innovation capability in Chinese state-owned high-tech enterprises," World Development, vol. 39, no. 7, pp. 1240-1248, 2011.

[20] K. Z. Zhou and C. B. Li, "How knowledge affects radical innovation: knowledge base, market knowledge acquisition, and internal knowledge sharing," Strategic Management Journal, vol. 33, no. 9, pp. 1090-1102, 2012.

[21] D. J. Teece, "Explicating dynamic capabilities: the nature and microfoundations of (sustainable) enterprise performance," Strategic Management Journal, vol. 28, no. 13, pp. 1319-1350, 2007.

[22] G. Yalcinkaya, R. J. Calantone, and D. A. Griffith, “An examination of exploration and exploitation capabilities: implications for product innovation and market performance," Journal of International Marketing, vol. 15, no. 4, pp. 63-93, 2007.

[23] Y. Lin and L.-Y. Wu, "Exploring the role of dynamic capabilities in firm performance under the resource-based view framework," Journal of Business Research, vol. 67, no. 3, pp. 407-413, 2014.

[24] S. Najafi-Tavani, Z. Najafi-Tavani, P. Naudé, P. Oghazi, and E. Zeynaloo, "How collaborative innovation networks affect new product performance: product innovation capability, process innovation capability, and absorptive capacity," Industrial Marketing Management, vol. 73, pp. 193-205, 2018.

[25] A. Capaldo, "Network structure and innovation: the leveraging of a dual network as a distinctive relational capability," Strategic Management Journal, vol. 28, no. 6, pp. 585-608, 2007.

[26] G. Ahuja, "Collaboration networks, structural holes, and innovation: a longitudinal study," Administrative Science Quarterly, vol. 45, no. 3, pp. 425-455, 2000.

[27] C. C. Phelps, "A longitudinal study of the influence of alliance network structure and composition on firm exploratory innovation," Academy of Management Journal, vol. 53, no. 4, pp. 890-913, 2010.

[28] R. Fang, B. Landis, Z. Zhang, M. H. Anderson, J. D. Shaw, and M. Kilduff, "Integrating personality and social networks: a meta-analysis of personality, network position, and work outcomes in organizations," Organization Science, vol. 26, no. 4, pp. 1243-1260, 2015.

[29] S. Donati, S. Zappalà, and V. González-Romá, "The influence of friendship and communication network density on individual innovative behaviours: a multilevel study," European Journal of Work and Organizational Psychology, vol. 25, no. 4, pp. 583-596, 2016.

[30] M. Fritsch and M. Kauffeld-Monz, "The impact of network structure on knowledge transfer: an application of social network analysis in the context of regional innovation networks," The Annals of Regional Science, vol. 44, no. 1, p. 21, 2010.

[31] C.-Y. Tseng, S.-C. Lin, D.-C. Pai, and C.-W. Tung, "The relationship between innovation network and innovation capability: a social network perspective," Technology Analysis \& Strategic Management, vol. 28, no. 9, pp. 1029-1040, 2016.
[32] J. Arsenyan, G. Büyüközkan, and O. Feyzioğlu, "Modeling collaboration formation with a game theory approach," Expert Systems with Applications, vol. 42, no. 4, pp. 2073-2085, 2015.

[33] S. Babu and U. Mohan, "An integrated approach to evaluating sustainability in supply chains using evolutionary game theory," Computers \& Operations Research, vol. 89, pp. 269283, 2018.

[34] L. Liu, Y. Huang, and X. Zhan, "The evolution of collective strategies in SMEs' innovation: a tripartite game analysis and application," Complexity, vol. 2019, Article ID 9326489, 15 pages, 2019.

[35] E. Mêgnigbêto, "Modelling the Triple Helix of universityindustry-government relationships with game theory: core, Shapley value and nucleolus as indicators of synergy within an innovation system," Journal of Informetrics, vol. 12, no. 4, pp. 1118-1132, 2018.

[36] K. Ritzberger and J. W. Weibull, "Evolutionary selection in normal-form games," Econometrica, vol. 63, no. 6, pp. 1371-1399, 1995.

[37] D. Friedman, "On economic applications of evolutionary game theory," Journal of Evolutionary Economics, vol. 8, no. 1, pp. 15-43, 1998. 